\title{
Supporting Student Veterans: Utilizing Game-Based Role-Plays with Virtual Humans to Build Military Cultural Competency and Helping Behaviors in Faculty and Staff
}

\author{
Chris A. Cate \\ Student Veterans of America \\ Glenn Albright \\ Baruch College, City University of New York
}

\begin{abstract}
Veterans and military service members enter the classroom with valuable life and leadership experience; however, transitioning to student life represents unique challenges. Like the larger veteran population, student veterans may bring to campus the negative aftereffects of their combat experiences in the form of post-traumatic stress, substance abuse, depression, and thoughts of suicide. To better support and retain the nation's 950,000 student veterans, higher-education institutions are beginning to train faculty and staff to more effectively understand and meet the needs of student-veteran populations. This study examines the impact of a new and innovative game-based virtual training simulation where users role-play with emotionally responsive virtual student veterans to understand the unique value veterans bring to campus, the obstacles they face in their pursuit of a college degree, effective tactics for managing challenging conversations, and the best practices for connecting student veterans exhibiting signs of psychological distress with appropriate support services. Longitudinal data showed significant $(p<.01)$ and sustained increases in learners' military cultural competency (which included knowledge about the common challenges facing the student veterans), and preparedness to manage classroom discussions around veteran-sensitive issues, to talk with student veterans about their military service, and if necessary to make a referral to the appropriate campus office. Data also showed significant $(p<.01)$ and sustained increases in gatekeeper skills, which included the learners' preparedness, likelihood, and self-efficacy to help a student veteran in psychological distress, which resulted in increased referrals to support services.
\end{abstract}




\section{Introduction}

Veterans and military service members represent an important portion of the higher-education population, with over 1 million veterans using their education benefits since 2008 (Department of Veterans Affairs, 2014). They share many attributes of other nontraditional populations, such as being adult learners and married college students; however, their experiences make them different from both traditional and nontraditional students. For example, student veterans and military service members bring a wealth of unique military experiences to the classroom due to their interaction with foreign cultures and the ensuing world perspective that can lead to more robust classroom discussions (Ackerman, DiRamio, \& Mitchell, 2009). In addition, soft skills developed through military service, such as goal setting, time management, and discipline, can aid student veterans in their studying and academic performance. However, student veterans may also bring to campus the negative aftereffects of their combat experiences in the form of post-traumatic stress (PTS), depression, and thoughts of suicide, as reported in the larger post-9/11 veteran population (Hoge, Auchterlonie, \& Milliken, 2006; Milliken, Auchterlonie, \& Hoge, 2007; Lapierre, Schwegler, \& LaBauve, 2007).

The prevalence of psychological distress among student veterans has not been thoroughly investigated or cataloged; however, several studies on the post-9/11 veteran population provide insights into student veterans and service members (Ramchand et al., 2010). Using meta-analysis strategies, Ramchand et al. (2010) found the PTS prevalence rate among the general population of Operation Iraqi Freedom (OIF) and Operation Enduring Freedom (OEF) veterans to be within the range of 5\% to 20\%, depending on the type of screening instrument used, the sampling procedures, and the definition of PTS used by the investigators. Milliken et al. (2007) found that $10.3 \%$ of OIF/OEF active-duty veterans and $13.0 \%$ of National Guard and Reservists were at risk of depression six months after returning from deployment. They also reported that $16.7 \%$ of OIF/OEF active-duty veterans and $24.5 \%$ of National Guard and Reservist veterans were at risk for PTS six months after returning from deployment. Over one fourth $(27.1 \%)$ of OIF/OEF active-duty veterans and over one third (35.5\%) of National Guard and Reservist veterans were found to be at mental health risk, defined by the authors as being at risk for at least one of the following: depression, PTS, suicidal ideation, interpersonal conflict, or aggressive ideation. These rates of PTS among the post-9/11 veteran population are higher than the rates found in college students generally (9.0\%) by Read, Ouimette, White, Colder, and Farrow (2011), but they are nearly even with the reported college-student prevalence of depression of 12.1\% (American College Health Association, 2014).

A lack of adequate research on psychological distress among the student veteran population makes it difficult to report how PTS and depression affect student veterans' persistence rates. Ackerman et al. (2009) found that student veterans with PTS reported more difficulty with concentration and focus, thus affecting their academic performance, which may affect their persistence. Yet, it is logical to presume that the effects psychological distress has on the nonveteran student population will also be present among student veterans. Psychological stressors among nonveteran students can have a negative effect on their college persistence, as evidenced by recent studies that have explored the effects of psychological stressors on postsecondary retention, which can provide further insight on the effects of psychological distress on student veterans' retention (Duncan, 2000; Kiuhara \& Huefner, 2008; Megivern, Pellerito, \& Mowbray, 2003; Smyth, Hockemeyer, Heron, Wonderlich, \& Pennebaker, 2008; Thompson, 2007). Megivern et al. (2003) found a link between academic performance and psychological symptoms, which also subsequently led to some students withdrawing from postsecondary institutions.

Duncan (2000) found an association between college students who report post-traumatic symptoms and their withdrawal from college. The study found a significant interaction $(p<.01)$ between traumatic stress and PTS as related to remaining in or withdrawing from college. PTS symptoms present at the second week of a student's freshman year were significantly related $(p<.05)$ to that student's college attendance in his or her fourth year, and students who experienced either more or stronger symptoms were less likely to be enrolled by their fourth year. Also, the number of students enrolled who 
reported PTS symptoms present at the second week consistently decreased with each successive semester; the greatest decrease occurred at the end of the first year of school. Therefore, student veterans with psychological distress may have a lower probability of persisting and completing their degrees.

Students with psychological distress are not new to postsecondary institutions. Postsecondary institutions have developed on-campus services and programs designed to support members of their student bodies who are experiencing psychological distress and research provided evidence that these campus program and services help mitigate some of the negative effects of psychological distress (DeStefano, Mellott, \& Petersen, 2001; Turner \& Berry, 2000; Wilson, Mason, \& Ewing, 1997). DeStefano et al. (2001) found that on-campus counseling services increased the academic, social, and emotional adjustments of at-risk students to the point where there were no significant differences $(p>.05)$ between the at-risk group and the control group. Wilson et al. (1997) reported that students who received counseling had $14 \%$ higher retention rates than their uncounseled peers. Turner and Berry (2000) also found that the postsecondary completion rates between students who received counseling and the general student population were equal. Considering that students in need of counseling are at risk of withdrawing from college, this finding illustrates the potential benefits of mental health counseling to enable students to adjust positively to college as well as persist in their pursuit of a college degree.

Students will only receive the benefits of these programs and services if they use them. In some cases, the school relies on a central point of contact trained for and dedicated to counseling veterans (Cook \& Kim, 2009); however, this method is inefficient and relies on the presumption that the student veteran will seek out the point of contact for help. Alternatively, faculty and campus-wide staff have more contact with student veterans and can provide referrals to on-campus support services for them, yet many colleges and universities do not provide training on veteran or military culture for their faculty or staff (Ryan, Carlstrom, Hughey, \& Harris, 2011), thereby limiting the ability of faculty and staff to provide help and referrals to student veterans and hindering student veterans' use of potentially beneficial campus support services.

\section{Literature Review}

\section{Gatekeeper Training}

Gatekeeper training involves teaching individuals to recognize the signs of psychological distress in others and to be able to approach and talk with those they are concerned about for the purpose of making a referral to mental health support services. Internationally, the United Nations has recommended that gatekeeper training be considered an important part in implementing an effective strategy to prevent suicide (United Nations Department for Policy Coordination and Sustainable Development, 1996). In this study, college and university faculty, staff, and administrators completed an online gatekeeper training simulation where they were taught to become aware of the signs of psychological distress in student veterans, such as those seen in PTS, substance abuse, anxiety disorders, depression, and thoughts of suicide. Additionally, the training taught them how to engage a student veteran they are concerned about in a conversation, and if necessary, motivate him or her to seek mental health support services.

Many gatekeeper training programs have demonstrated increases in knowledge and self- efficacy, but relatively few studies have examined changes in gatekeeper behaviors (Aseltine \& DeMartino, 2004; Cross, Matthieu, Lezine, \& Knox, 2010; Isaac et al., 2009; Kalafat \& Gagliano, 1996; Mann et al., 2005; Schurtz, Cerel, \& Rodgers, 2010; Wyman et al., 2008). Some studies examined the impact of gatekeeper training on knowledge, attitudes, and gatekeeper behaviors (Albright, 2013; Albright et al., 2012; Cross et al., 2011) as well as self-disclosed suicide attempts (Aseltine \& DeMartino, 2004; Knox, Litts, Talcott, Feig, \& Caine, 2003; Eggert, Thompson, Randell, \& Pike, 2002).

The majority of gatekeeper training programs do not employ active-learning strategies such as role rehearsal, in which learners practice gatekeeper skills by role-playing with an individual who is portraying himself or herself as being a distressed or suicidal person, to aid skill development in the 
learner (Cross et al., 2011). Active learning involves learning by doing as opposed to solely listening. This process can involve reading, discussing, problem solving, role-playing, and participating in learning groups, games, simulations, and other activities that impact learner knowledge, skills, and attitudes (Bonwell \& Eison, 1991). There are hundreds of journal articles including meta-analytic studies that examine the impact of active-learning strategies as applied to multiple disciplines; thus, to stay within the framework of this study, we are focusing on role-play as the main active-learning strategy.

Researchers are exploring the implications of using role-plays during gatekeeper trainings to allow people the opportunity to practice the new skills. Cross et al. (2011) found that the use of role-plays or behavioral rehearsal resulted in higher overall gatekeeper skills immediately following training and at a 3-month follow-up compared to those that did not participate in a role-play; however there was a significant reduction in both groups' scores at the 3-month follow-up.

Effective role-plays must have the proper context and simulate narratives that represent realworld scenarios. Otherwise the learning process is limited, and there may be a decreased likelihood to return for further training. To approximate a real-world experience, Cross et al. (2011) use trained experimenters in conducting face-to-face role-plays to train gatekeepers.

Online role-play training simulation models were found to be an effective tool to engage military families in taking an active role in motivating veterans to seek help at a Veterans Administration (VA) hospital (Albright et al., 2011). Further support of the impact of this type of active learning used to train gatekeepers is seen in a meta-analytic study in which a total of 12,410 middle- and high-school educators, college faculty, staff, and students completed one of five online role-play training simulations (Albright et al., 2014b). Baseline, post-training, and 3-month follow-up data was collected via the Gatekeeper Behavior Scale (GBS), which measured gatekeeper attitudes of preparedness, likelihood or behavioral intent, and self-efficacy to engage in gatekeeper behaviors. Baseline and follow-up gatekeeper behaviors were also collected and included the self-reported number of students identified, approached, and referred to mental health support services. Composite effect size for pre- and posttraining measures of preparedness, likelihood, and self-efficacy to engage in gatekeeper behaviors was large at 0.72 . Effect sizes comparing pretraining to posttraining preparedness was 0.70 , likelihood was 0.35 , and self-efficacy was 0.42. Changes in gatekeeper behaviors, including increases in the number of distressed students identified, approached, and referred to mental health support services, was 0.21 . This data supports the use of the game-based role-play simulations using virtual humans to train gatekeepers.

The gatekeeper training simulation used in this study is called Veterans on Campus (VOC) and was developed by a vendor, Kognito, with input from veteran services organizations, nationally recognized mental health experts, and over 75 faculty and student veterans in the United States. Introduced in 2012, VOC is listed in Section III of the Suicide Prevention Resource Center of the American Foundation for Suicide Prevention Best Practices Registry for Suicide Prevention (Suicide Prevention Resource Center, 2014). Section III: Adherence to Standards lists suicide prevention programs and practices whose content has been reviewed for accuracy, likelihood of meeting objectives, and adherence to program design standards.

\section{Training Simulations}

VOC is a 30-minute online training simulation designed to educate faculty and staff about (1) the unique value student veterans bring to campus, (2) obstacles veterans may face in their pursuit of a college degree, (3) effective techniques for managing classroom discussions around topics that may be sensitive to veterans, and (4) best practices for connecting student veterans exhibiting signs of psychological distress with appropriate support services. VOC is built around a series of miniconversation games where users interact with intelligent, fully animated, and emotionally responsive virtual student veterans experiencing a challenging situation or psychological distress. These virtual humans possess their own personalities and memories and adapt their behaviors to the learners' conversation tactics throughout the role-play to provide the player with a highly realistic experience, as if they were interacting with real student veterans. Within these conversations, learners practiced using 
motivational interviewing (MI) skills in role-plays. A virtual coach provides ongoing positive feedback when the learner employs effective MI conversation strategies and corrective feedback in response to non-MI or poor conversation choices, such as being judgmental or critical, or attempting to diagnose a problem. Additionally, the virtual veterans that users role-play with react verbally and nonverbally to the conversation tactics that learner selects, thus providing immediate feedback to the learner. The participant completes the training by successfully helping each veteran resolve a challenge he or she is facing due to individual transitions that result in an effective referral to support services.

\section{Motivational Interviewing}

In this study participants learn how to employ a set of MI techniques originally designed by clinical psychologists for use in counseling sessions with problem drinkers (Miller, 1983). MI is a goaloriented, client-centered counseling approach designed to actively engage clients in identifying their problems and to increase their intrinsic motivation to change their behavior (Miller \& Rollnick, 2012). Numerous meta-analyses have demonstrated the efficacy of MI in a wide variety of clinical contexts, including weight loss, smoking cessation, adolescent substance abuse, problem drinking, and primary care (Armstrong et al., 2011; Burke, Arkowitz, \& Menchola, 2003; Heckman, Egleston, \& Hofmann 2010; Jensen et al., 2011; Lai, Cahill, Qin, \& Tang, 2010; Lundahl \& Burke, 2009; Rubak, Sandbæk, Lauritzen, \& Christensen, 2005; VanBuskirk \& Wetherell, 2013; Vasilaki, Hosier, \& Cox, 2006). The VOC training integrated the four core MI skills, which include (1) asking open-ended questions, (2) providing affirmation, (3) reflective listening (listening closely and periodically confirming comprehension), and (4) summarizing client self-assessments. These techniques are associated with effective therapy and are thought to encourage strong rapport and to support behavioral change (Miller \& Rollnick, 2012).

\section{Methods}

This quasi-experimental post-hoc study examines the impact of the VOC training simulation on 758 faculty, staff, and administrators from 20 four-year colleges or universities and four community colleges.

\section{The Training}

To complete the training, users enter an online environment and engage in simulated role-play conversations with three emotionally responsive virtual student veterans. Participants practice role-plays with each simulated veteran and receive ongoing corrective or reinforcing feedback from a virtual coach. The participant completes the training by helping each veteran successfully resolve a challenge he or she is facing due to his or her transition. In this process, students learn to use MI tactics such as asking openended questions and reflective listening to build trust and motivate the virtual veteran to seek help.

\section{Procedure and Measurers}

All participants were recruited by e-mail, mailbox flyer, poster, or a colleague. Campus-wide emails were from the chancellor, provost, vice president of student services, counseling center director, and campus-wide stakeholders, such as the veteran's resource center or student veteran's organizations, such as chapters of the Students Veterans of America. Before beginning the study, participants were informed that their participation was voluntary and that there would be no negative consequences if they decided not to participate. They were also informed that all identifying information and answers would be confidential and that their results would be combined with responses from other survey participants and might be presented at scientific or medical meetings or published in scientific journals. Lastly, they were informed that by submitting their answers to the survey, they were giving their consent and agreeing that they had read and understood the nature of their participation. 


\section{Gatekeeper Behaviors}

Table 1 Gatekeeper Behavior Scale

\begin{tabular}{|c|c|c|c|}
\hline Subscale & Number & Item & Response scale \\
\hline \multirow[t]{6}{*}{ Preparedness } & \multicolumn{3}{|c|}{ How would you rate your preparedness to: } \\
\hline & 1 & $\begin{array}{l}\text { Recognize when a student veteran's behavior is a } \\
\text { sign of psychological distress }\end{array}$ & \multirow{5}{*}{$\begin{array}{l}\text { 1- Very low } \\
\text { 2- Low } \\
\text { 3- Medium } \\
\text { 4- High } \\
\text { 5- Very high }\end{array}$} \\
\hline & 2 & $\begin{array}{l}\text { Recognize when a student veteran's physical } \\
\text { appearance is a sign of psychological distress }\end{array}$ & \\
\hline & 3 & $\begin{array}{l}\text { Discuss with a student veteran your concern } \\
\text { about the signs of psychological distress they are } \\
\text { exhibiting }\end{array}$ & \\
\hline & 4 & $\begin{array}{l}\text { Motivate student veterans exhibiting signs of } \\
\text { psychological stress to seek help }\end{array}$ & \\
\hline & 5 & $\begin{array}{l}\text { Recommend mental health support services (such } \\
\text { as the counseling center) to a student veteran } \\
\text { exhibiting signs of psychological distress }\end{array}$ & \\
\hline \multirow[t]{2}{*}{ Likelihood } & 6 & $\begin{array}{l}\text { How likely are you to discuss your concerns with } \\
\text { a student veteran exhibiting signs of } \\
\text { psychological distress? }\end{array}$ & \multirow{2}{*}{$\begin{array}{l}\text { 1-Very unlikely } \\
\text { 2-Unlikely } \\
\text { 3-Likely } \\
\text { 4-Very likely }\end{array}$} \\
\hline & 7 & $\begin{array}{l}\text { How likely are you to recommend mental } \\
\text { health/support services (such as the counseling } \\
\text { center) to a student veteran exhibiting signs of } \\
\text { psychological distress? }\end{array}$ & \\
\hline \multirow[t]{5}{*}{ Self-Efficacy } & \multicolumn{2}{|c|}{$\begin{array}{l}\text { Please rate how much you agree/disagree with the } \\
\text { following statements: }\end{array}$} & \multirow{5}{*}{$\begin{array}{l}\text { 1- Strongly disagree } \\
\text { 2- Disagree } \\
\text { 3-Agree } \\
\text { 4-Strongly agree }\end{array}$} \\
\hline & 8 & $\begin{array}{l}\text { I feel confident in my ability to discuss my } \\
\text { concern with a student veteran exhibiting signs of } \\
\text { psychological distress. }\end{array}$ & \\
\hline & 9 & $\begin{array}{l}\text { I feel confident in my ability to recommend } \\
\text { mental health support services to a student } \\
\text { veteran exhibiting signs of psychological distress. }\end{array}$ & \\
\hline & 10 & $\begin{array}{l}\text { I feel confident that I know where to refer a } \\
\text { student veteran for mental health support. }\end{array}$ & \\
\hline & 11 & $\begin{array}{l}\text { I feel confident in my ability to assist a student } \\
\text { veteran seeking help. }\end{array}$ & \\
\hline
\end{tabular}

There were three surveys used in this study, which included a survey administered just before training to collect baseline measures, a survey administered immediately after the training, and a 3-month follow-up survey to assess durability of learning. All or some of the surveys included measures of (1) gatekeeper attitudes, (2) gatekeeper behaviors, (3) military cultural competency, (4) means efficacy, and (5) demographics. 


\section{Gatekeeper Attitudes}

All three surveys included the 11-item Gatekeeper Behavior Scale (GBS), a validated assessment tool used to determine the impact of online virtual-human gatekeeper training simulations (Albright et al., 2014). The GBS's items measure changes in attitudes and intentions by assessing three dimensions or subscales: learner preparedness and likelihood and self-efficacy to engage in gatekeeper behaviors. The preparedness composite comprises five items that indicate how prepared the learner was to (1) identify a student veteran in psychological distress as evidenced by his or her behavior, (2) identify a student veteran in psychological distress as evidenced by his or her appearance, (3) discuss his or her concern with the student veteran, (4) motivate a student veteran in psychological distress to seek help, and (5) recommend mental health support services. The second is the likelihood or behavioral intent that included two items on how likely the learner is to (1) discuss concerns and (2) recommend mental health services. The third construct is self-efficacy or confidence in one's ability to (1) discuss one's concern with a student veteran in psychological distress, (2) assist a student veteran seeking help, (3) recommend mental health support services, and (4) know where to refer student veterans for support services. The GBS's construct and content validity were assessed via confirmatory factor analysis and had internal reliabilities of .95 for preparedness, .85 for likelihood, and .94 for self-efficacy. In this current study, all GBS items that contained the word "student" had veteran added so that they read "student veteran," and there was no data examining the impact on validity because of this change (see Table 1 for the GBS).

The pretraining and 3-month follow-up surveys contained four items that assessed gatekeeper behaviors. The phrase "Over the past two academic months how many student veterans have you" was followed by the four items: (1) spoken with about their military service, (2) been concerned about due to psychological distress, (3) been approached by to talk to about their concern, and (4) referred to support services. Gatekeeper behaviors were also measured in the 3-month follow-up survey, in which users were asked to respond on a 4-point Likert scale from "strongly agree" to "strongly disagree" with the statement "As a result of taking the VOC course there has been an increase in the number of student veterans that I have" (1) recognized as exhibiting signs of psychological distress, (2) approached to discuss my concern about their psychological distress, (3) referred for mental health support, and (4) referred to non-mentalhealth campus offices.

\section{Military Cultural Competency}

The pretraining, posttraining, and follow-up surveys contained five items that measured military cultural competency (MCC). MCC is comprised of the knowledge, skills, and attitudes necessary to understand the veteran population and their families (Gleeson \& Hemmer, 2014). The authors point out the importance of healthcare providers developing MCC to be more effective in helping veteran populations and their families. There are no validated measures of MCC in higher educational institutions; thus, we developed five items where participants were asked about (1) how prepared they were to talk with a student veteran about his or her military service, (2) knowledge about the common challenges facing the student veteran population, (3) preparedness to manage classroom discussions around veteran-sensitive issues, (4) comfort in talking to a student veteran about his or her military service, and (5) preparedness to refer student veterans to appropriate campus offices. This last item was included because there are many resources within higher education that a veteran can be referred to beyond a mental health counseling center, such as career services, a disabilities center, a student veteran association, and so on. Knowing the potential needs of student veterans and understanding their life circumstances is part of MCC. Response options were set on a 4-point Likert scale that ranged from "strongly disagree" to "strongly agree," except for the preparedness to manage classroom discussions around veteran sensitive issues, which was on a 5-point scale ranging from "very low” to "very high."

\section{Means Efficacy}

Means efficacy is defined by Eden, Ganzach, Flumin-Granat, and Zigman (2010) as an individual's belief in the utility of the tools available for performing a job and is correlated with changes in behavior. Means efficacy items were only in the posttraining survey and were based on a 5-point Likert 
scale that ranged from "not at all or to a very little extent” to "to a very great extent" and included measures of the training's (1) usefulness, (2) ease of use, (3) well constructedness ("likely to help you with student veterans in psychological distress"), (4) "being based on scenarios that are relevant to you and student veterans," and (5) "aid you in getting timely help to your veteran student."

\section{Results}

\section{Demographics}

Participants who responded to the demographic questions showed that the average age was 43.8 years $(S D=13.4)$ with $67 \%$ female. In terms of race, $69 \%$ responded as white/Caucasian, $18 \%$ Hispanic or Latino, 8\% black or African American, 4\% Asian, and 1\% American Indian/Alaskan Native. The average number of years worked at a college/university was $10.2(S D=8.6)$, and roles included full-time faculty (14\%), part-time faculty (19\%), staff member (65\%), or resident advisor/student leader (2\%). A total of $22.8 \%$ of participants stated they had received prior gatekeeper training, with $5.4 \%$ stating that they had been trained as a mental health practitioner.

\section{GBS Results}

\section{Preparedness}

A repeated-measures analysis of variance (ANOVA) revealed statistically significant increases in participants' GBS preparedness composite score to recognize, discuss, motivate, and help student veterans in psychological distress between pretraining, posttraining, and follow-up scores $F(2,758)=927.4, p<.01$. Bonferroni's correction indicated that the posttraining and 3month follow-up scores were both significantly higher when compared to pretraining baseline scores. Follow-up scores were statistically significantly lower than posttraining scores (but still statistically significantly higher compared to baseline), indicating some reduction in preparedness over time (see Table 2).

\section{Likelihood}

A repeated-measures ANOVA showed statistically significant increases in participants' GBS composite scores of likelihood to help student veterans in psychological distress between pretraining, posttraining, and follow-up scores $F(2,742)=228.0, p<.01$.

Bonferroni's correction indicated that the posttraining and 3-month follow-up scores were both statistically significantly higher than pretraining baseline scores. Follow-up scores were statistically significantly lower than posttraining scores (though still significantly higher than baseline), indicating some reduction in preparedness over time (see Table 2).

Table 2 Comparison of GBS, Military Cultural Competency and Gatekeeper Behavior Measures Over Time

\begin{tabular}{|c|c|c|c|c|c|c|}
\hline \multirow[b]{2}{*}{ Composite measure } & \multirow[b]{2}{*}{$\mathrm{N}$} & \multirow{2}{*}{$\begin{array}{l}\text { Pre } \\
\text { M (SD) }\end{array}$} & \multirow{2}{*}{$\begin{array}{l}\text { Post } \\
\text { M (SD) }\end{array}$} & \multirow{2}{*}{$\begin{array}{l}\text { Follow-up } \\
\mathrm{M}(S D)\end{array}$} & \multirow[b]{2}{*}{$F$} & \multirow[b]{2}{*}{$t$} \\
\hline & & & & & & \\
\hline Preparedness & 758 & $2.94(.85)$ & $3.87(.67)$ & $3.78(.66)$ & $927.35^{*}$ & - \\
\hline Likelihood & 743 & $2.94(.71)$ & $3.40(.56)$ & $3.28(.59)$ & $287.0 *$ & - \\
\hline Self-efficacy & 726 & $2.70(.65)$ & $3.30(.46)$ & $3.17(.50)$ & $520.7 *$ & - \\
\hline Military cul. comp. & 736 & $2.92(.62)$ & $3.33(.48)$ & $3.27(.50)$ & $274.0 *$ & - \\
\hline Behaviors $^{1}$ & 258 & $1.93(.54)$ & - & $2.75(.11)$ & - & 1.41 \\
\hline
\end{tabular}

Note. Only those who indicated having veterans in their classrooms were included. ${ }^{*} p<.01$ 


\section{Self-Efficacy}

The third repeated-measures ANOVA showed statistically significant increases in participants' GBS composite scores of self-efficacy with regard to helping student veterans in psychological distress between pretraining, posttraining, and follow-up scores $F(2,725)=520.37, p<.01$. Follow-up scores were statistically significantly lower than posttraining scores (but still statistically significantly higher than baseline), indicating some reduction in self-efficacy over time (see Table 2).

\section{Gatekeeper Behaviors}

To investigate changes in gatekeeper behaviors from baseline to 3-month follow-up, we combined into a composite variable the four behavior items that included the self-reported number of student veterans that participants (1) had spoken with about their military service, (2) were concerned about due to psychological distress, (3) had approached to talk to about their concern, and (4) had referred to support services. The pretraining and follow-up composite scores for those participants that reported that they had a student veteran in their classroom $(N=200)$ were compared using a paired samples t-test. The result indicated the composite behavior score at 3-month follow-up compared to before VOC training was trending toward a statistically significant increase, $t(257)=1.41, p=.160$ (see Table 2).

Ultimately, the impact of training comes down to the answer to the question, does the training increase gatekeeper behaviors? Thus, to further examine behavior change, we included Likert scale items in the 3-month follow-up survey in which participants were asked to respond to the statement "As a result of taking the VOC course there has been an increase in the number of student veterans that I have." Results showed that (1) 52.5\% agreed or strongly agreed with the statement that VOC increased recognition of those student veterans exhibiting signs of psychological distress, (2) $48 \%$ agreed or strongly agreed that the training increased the number of student veterans approached to discuss their concern about their psychological distress, (3) 45.5\% agreed or strongly agreed that there were increases in the number of student veterans referred for mental health support services, and (4) $51 \%$ agreed or strongly agreed with the statement that VOC increased referrals. Responses to these items showed an increase in gatekeeper behaviors; however, the measures are self-reported, and validity and reliability have not been established.

\section{Military Cultural Competency}

MCC was administered in the pretraining, posttraining, and follow-up surveys, and was comprised of five Likert scale items in which participants reported on (1) how prepared they were to talk with a student veteran about his or her military service, (2) knowledge about the common challenges facing the student veteran population, (3) preparedness to manage classroom discussions around veteransensitive issues, (4) comfort in talking to a student veteran about his or her military service, and (5) preparedness to refer student veterans to appropriate campus offices. Reponses to these items were used to form a composite score and a repeated-measures ANOVA showed that there was statistically significant increases in the composite MCC score. Pre, post, and follow-up scores $F(2,735)=274.0, p<$ .01. Bonferroni's correction indicated that the posttraining and 3-month follow-up scores were statistically significantly higher than pretraining scores. Follow-up scores were statistically significantly lower than posttraining scores yet remained statistically significantly higher than baseline, indicating some reduction in MCC over time (see Table 2).

The pretraining, posttraining, and follow-up measures from the composite scores drawn from the GBS, military cultural competency, and gatekeeper behavior can be seen in Figure 1.

\section{Means Efficacy}

All measures of means efficacy were high for the trainings and rated it as being a useful tool, well constructed, easy to use, "likely to help the learner with a student in psychological distress," based on scenarios that are relevant and aiding the learner in getting timely help for the student (see Table 3). 
Reaction data also showed that 99\% of participants rated the course "good" to "excellent," 98\% would recommend VOC to other faculty and staff, and $96 \%$ stated that all faculty, staff, and administrators in their academic institution should take this course. Lastly, 38\% of participants either agreed or strongly agreed that as a result of the training there has been an increase in the number of conversations they have had with other faculty, staff, and/or administrators regarding student veterans they are concerned about.

\section{Discussion}

This study provides support for using the online VOC role-play training simulation to increase gatekeeper skills and MCC in university and college faculty, staff, and administrators to support student veterans. To investigate whether skills were retained over time, we compared outcome measures collected at baseline and 3-month follow-up for the gatekeeper composite variables of preparedness, likelihood or behavioral intent, and self-efficacy to help student veterans, as well as MCC. All three gatekeeper composite variables and MCC remained statistically significantly higher when comparing baseline to 3month follow-up, even though there was an expected decline in these scores from posttraining to followup. Thus, the analyses imply that the training has a lasting effect on gatekeeper skills and MCC, yet the decline in training effect also implies that it would be useful to have refresher training at periodic intervals, such as by including this training with other annual training for faculty, staff, and administrators. The composite gatekeeper behavior score increased and was trending toward significant levels from baseline to follow-up. Further support for increases in gatekeeper behavior were seen when $45 \%$ of participants who had at least one veteran in their class stated they made a referral of a student veteran to mental health services and 51\% to non-mental-health campus services. Lastly, means efficacy data was very high, indicating that users believed in the effectiveness of the tool, which has been shown to impact behavior.

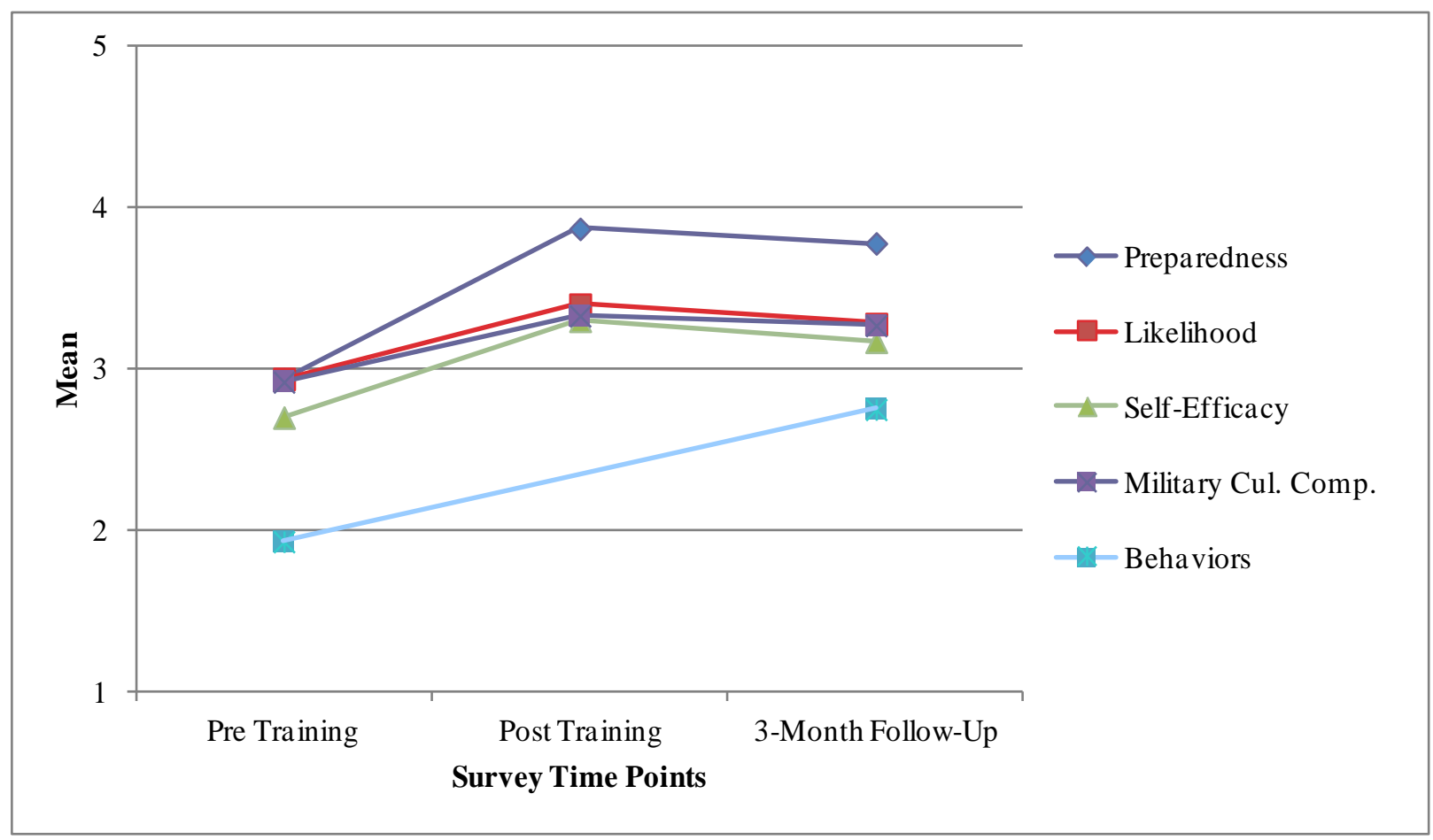

Figure 1. Comparison of GBS and military cultural competency measures over time 
Table 3 Means Efficacy Course Ratings

\begin{tabular}{llllll}
\hline & $\begin{array}{l}\text { To a very } \\
\text { great extent }\end{array}$ & $\begin{array}{l}\text { To a great } \\
\text { extent }\end{array}$ & $\begin{array}{l}\text { To some } \\
\text { extent }\end{array}$ & $\begin{array}{l}\text { To a little } \\
\text { extent }\end{array}$ & $\begin{array}{l}\text { Not at all or a } \\
\text { very little extent }\end{array}$ \\
\hline A useful tool & $33.5 \%$ & $45.1 \%$ & $19.4 \%$ & $1.7 \%$ & $0.0 \%$ \\
Well constructed & $41.0 \%$ & $47.2 \%$ & $10.1 \%$ & $1.4 \%$ & $0.0 \%$ \\
Easy to use & $55.1 \%$ & $37.6 \%$ & $5.1 \%$ & $1.0 \%$ & $0.0 \%$ \\
$\begin{array}{l}\text { Likely to help you with student } \\
\text { veterans in psychological } \\
\text { distress }\end{array}$ & & & & \\
$\begin{array}{l}\text { Based on scenarios that are } \\
\text { relevant to you and student } \\
\text { veterans }\end{array}$ & $45.5 \%$ & $42.0 \%$ & $19.7 \%$ & $3.8 \%$ & $0.3 \%$ \\
$\begin{array}{l}\text { Aid you in getting timely help } \\
\text { to your veteran student }\end{array}$ & $33.5 \%$ & $43.9 \%$ & $17.7 \%$ & & \\
\hline
\end{tabular}

\section{Comments and Limitations}

\section{Comments}

Data showing statistically significant and sustained increases in the GBS and MCC, coupled with self-reported increases in gatekeeper behaviors and high means efficacy, strongly suggest that VOC is an effective tool to train faculty and staff to better support student veterans. This includes understanding the common challenges student veterans face, talking to them about their military service, and managing classroom discussions around veteran-sensitive issues. The training is also effective in developing learners' gatekeeper skills, including recognizing when a student veteran's appearance or behavior is of concern, such as in depression, in which the veteran may look disheveled, stop attending class, or be chronically late, disengaged, or exhibit poor academic performance. These indicators can overlap into PTS, in which a student veteran might find it difficult to concentrate due to being easily distracted, easy to anger, or seeming anxious and/or withdrawn. These and other indicators show that the student veteran may be in psychological distress, and knowing how to identify, approach, talk to, and if necessary motivate him or her to seek appropriate help and support is paramount.

Online virtual environments also offer the ability to explore situations that would be stressful in real life (Mantovani, Castelnuovo, Gaggioli, \& Riva, 2003). For example, one study reported that medical students found face-to-face role-play embarrassing and stressful compared to role-play in Second Life (Hamilton et al., 2014). Similarly, although socially anxious persons disclose less personal information in normal face-to-face interactions than do less anxious persons (Reno \& Kenny, 1992), several studies reported that socially anxious participants disclosed significantly more information when communicating with virtual humans (Kang \& Gratch, 2010; Lucas, Gratch, King, \& Morency, 2014).

Beyond the outcome data from this study, the authors feel that there are several important advantages that support utilizing the online role-play gatekeeper simulation model as opposed to face-toface training. The first is that role-playing with virtual humans may reduce situational factors that compromise the effectiveness of face-to-face role-plays, such as performing in front of peers, instructors, and other role-players, which can cause embarrassment or social evaluative threat (Nestel \& Tierney, 
2007). Both negative emotions in general, and social evaluative threat in particular, are known to impede cognitive performance (Baumeister, Twenge, \& Nuss, 2002; Payne et al., 2006). Another advantage is that once a virtual gatekeeper simulation is developed, it is sustainable. There are no costs for training, hiring, and maintaining professional instructors, which is especially onerous if one is scaling up to implement training on a state or national level. Additionally, this online training eliminates the need for travel expenses and the cost of participants being pulled away from their work, especially in rural areas.

Another advantage is being able to provide realistic online role-plays to support MI skills building that integrate continual feedback in a safe and confidential learner environment, such as in the privacy of one's office or home, with high fidelity. Training fidelity refers to the quality of delivery across all trainers. To ensure high fidelity, the learning experience must be standardized to each participant every time they enter a role-play, which means consistently delivering accurate knowledge, realistic and engaging role-plays, and appropriate feedback. VOC is game-based, so you are not depending on the skill and experience of the trainers and their knowledge of the population they are training. In the game-play, each user can have an entirely different experience depending on his or her choice of conversation tactic as he or she navigates through the role-plays, thus ensuring high fidelity. The high fidelity of VOC is in part due to a comprehensive and iterative development process used in constructing the simulation, which involved integrating the knowledge and experience of nationally recognized subject matter experts, and beta testing by many end-users and students.

It is also important to note that once participants are trained, they must have easy access to information about where to refer the individual they are concerned about, or they may not be as likely to engage in gatekeeper behaviors. To address this concern, online training simulations such as VOC can easily direct participants with the location of campus, institutional, or local resources to link student veterans to needed support services.

Finally, in the 3-month follow-up survey, we asked participants if there had been an increase in the number of conversations they had with other faculty, staff, or administrators regarding student veterans they were concerned about. Over one third reported increases in the number of conversations. This result may imply that as the number of people trained increases, so will conversations within an institution regarding understanding and supporting student-veteran mental health initiatives. This may have potentially profound implications because there might exist opportunities to impact overall institutional awareness, which will hopefully provide student veterans with the recognition and support they so richly earned and deserve.

\section{Limitations}

One limitation is that this field study, as do many others, utilized a quasi-experimental design that applied a post-hoc analysis. Future studies should employ a randomized control group design to examine the impact on outcome measures. Another limitation is that most participants self-selected into the study, meaning that individuals who elected to take the training may be disproportionately predisposed to assuming a "helper role." This possible confound is found in most all gatekeeper training programs and is especially true for face-to-face programs where the learner must be at a physical location for a specific time/date. Further, changes in actual referrals to mental and non-mental-health support services were selfreported due to a number of concerns, including issues surrounding privacy of data. Future research should be aimed at documenting whether those student veterans who were referred actually followed through. Finally, because participants reported an increased number of conversations with their colleagues about student veterans and mental health, future studies should include a sociological approach to determine the impact of these types of gatekeeper training simulations on institutional culture. It is in the interest of national public health initiatives to better understand how technology can be leveraged to have an impact on early detection and referral to treatment of those who are in need of help. 


\section{References}

Ackerman, R., DiRamio, D., \& Mitchell, R. (2009). Transitions: Combat veterans as college students. New Directions for Student Services, 126, 5-14. doi: 10.1002/ss.311.

Albright, G. (2013, November). Building the capacity of educators to support primary prevention and early intervention goals with youth at risk for psychological distress. In 141st APHA Annual Meeting (November 2-November 6, 2013). APHA.

Albright, G., Davidson, J., Goldman, R., Shockley, K., \& Tommons-Mitchell, J. (2014a). Development and validation of the Gatekeeper Behavior Scale: A tool to assess suicide prevention gatekeeper trainings. Manuscript submitted for review.

Albright, G., Davidson, J., Goldman, R., Shockley, K., Eastgard, S., \& Himmel, J. (2014b). Utilizing emotionally responsive virtual human role-play simulations to train users to identify, talk to and refer students in psychological distress including those at risk for suicide: A meta-analysis. Manuscript submitted for publication.

Albright, G., Goldman, R., Shockley, K. M., McDevitt, F., \& Akabas, S. (2011). Using an avatar-based simulation to train families to motivate veterans with post-deployment stress to seek help at the VA. Games for Health: Research, Development, and Clinical Applications, 1(1), 21-28. doi:10.1089/g4h.2011.0003.

American College Health Association. (2014). American College Health Association-National college health assessment II: Undergraduate students reference group data report spring 2014. Hanover, MD: American College Health Association.

Armstrong, M. J., Mottershead, T. A., Ronksley, P. E., Sigal, R. J., Campbell, T. S., \& Hemmelgarn, B. R. (2011). Motivational interviewing to improve weight loss in overweight and/or obese patients: A systematic review and meta-analysis of randomized controlled trials. Obesity Reviews, 12(9), 709-723. doi: 10.1111/j.1467-789X.2011.00892.x

Aseltine, R. H., Jr., \& DeMartino, R. (2004). An outcome evaluation of the SOS suicide prevention program. American Journal of Public Health, 94(3). doi: 10.2105/AJPH.94.3.446

Baumeister, R. F., Twenge, J. M., \& Nuss, C. K. (2002). Effects of social exclusion on cognitive processes: Anticipated aloneness reduces intelligent thought. Journal of Personality and Social Psychology, 83(4), 817. doi:10.1037/0022-3514.83.4.817

Bonwell, C. C., \& Eison, J. A. (1991). Active learning: Creating excitement in the classroom. 1991 ASHE-ERIC higher education reports. ERIC Clearinghouse on Higher Education, The George Washington University, One Dupont Circle, Suite 630, Washington, DC 20036-1183.

Burke, B. L., Arkowitz, H., \& Menchola, M. (2003). The efficacy of motivational interviewing: A metaanalysis of controlled clinical trials. Journal of Consulting and Clinical Psychology, 71(5), 843. doi:10.1037/0022-006X.71.5.843

Cook, B., \& Kim, Y. (2009). From soldier to student: Easing the transition of service members on campus. Washington, DC: American Council on Education. Retrieved from http://www.acenet.edu/news-room/Documents/From-Soldier-to-Student-Easing-the-Transitionof-Service-Members-on-Campus.pdf

Cross, W. F., Seaburn, D., Gibbs, D., Schmeelk-Cone, K., White, A. M., \& Caine, E. D. (2011). Does practice make perfect? A randomized control trial of behavioral rehearsal on suicide prevention gatekeeper skills. The Journal of Primary Prevention, 32(3-4), 195-211. doi:10.1007/s10935011-0250-z 
Cross, W., Matthieu, M. M., Lezine, D., \& Knox, K. L. (2010). Does a brief suicide prevention gatekeeper training program enhance observed skills? Crisis: The Journal of Crisis Intervention and Suicide Prevention, 31(3), 149. doi:10.1027/0227-5910/a000014

Department of Veterans Affairs. (2014). Department of Veterans Affairs, Veterans Benefits Administration, Annual Benefits Reports, 2000 to 2013. Washington, D.C. Retrieved 12 1, 2014, from http://www.va.gov/vetdata/docs/Utilization/EducNation 2013.xls

DeStefano, T. J., Mellott, R. N., \& Petersen, J. D. (2001). A preliminary assessment of the impact of counseling on student adjustment to college. Journal of College Counseling, 4(2), 113-121.

Duncan, R. D. (2000). Childhood maltreatment and college drop-out rates: Implications for child abuse researchers. Journal of Interpersonal Violence, 15(9), 987-995.

Eden, D., Ganzach, Y., Flumin-Granat, R., \& Zigman, T. (2010). Augmenting means efficacy to boost performance: Two field experiments. Journal of Management, 36(3), 687-713.

Eggert, L. L., Thompson, E. A., Randell, B. P., \& Pike, K. C. (2002). Preliminary effects of brief school-based prevention approaches for reducing youth suicide-Risk behaviors, depression, and drug involvement. Journal of Child and Adolescent Psychiatric Nursing, 15(2), 48-64. doi:10.1111/j.1744-6171.2002.tb00326.x

Gleeson, T. D., \& Hemmer, P. A. (2014). Providing care to military personnel and their families: How we can all contribute. Academic Medicine: Journal of the Association of American Medical Colleges, 89(9), 1201-1203. doi:10.1097/ACM.0000000000000368

Hamilton, G., Ortega, R., Hochstetler, V., Pierson, K., Lin, P., \& Lowes, S. (2014). Teaching communication skills to hospice teams comparing the effectiveness of a communication skills laboratory with in-person, Second Life, and phone role-playing. American Journal of Hospice and Palliative Medicine, 31(6), 611-618. doi: 10.1177/1049909113504481

Heckman, C. J., Egleston, B. L., \& Hofmann, M. T. (2010). Efficacy of motivational interviewing for smoking cessation: A systematic review and meta-analysis. Tobacco Control, 19(5), 410-416.

Hoge, C. W., Auchterlonie, J. L., \& Milliken, C. S. (2006). Mental health problems, use of mental health services, and attrition from military service after returning from deployment to Iraq or Afghanistan. JAMA: Journal of the American Medical Association, 295(9), 1023-1032.

Isaac, M., Elias, B., Katz, L. Y., Belik, S. L., Deane, F. P., Enns, M. W., \& Sareen, J. (2009). Gatekeeper training as a preventative intervention for suicide: A systematic review. Canadian Journal of Psychiatry-Revue Canadienne de Psychiatrie, 54(4), 260-268.

Jensen, C. D., Cushing, C. C., Aylward, B. S., Craig, J. T., Sorell, D. M., \& Steele, R. G. (2011). Effectiveness of motivational interviewing interventions for adolescent substance use behavior change: A meta-analytic review. Journal of Consulting and Clinical Psychology, 79(4), 433. doi:10.1037/a0023992

Kalafat, J., \& Gagliano, C. (1996). The use of simulations to assess the impact of an adolescent suicide response curriculum. Suicide and Life-Threatening Behavior, 26(4), 359-364. doi:10.1111/j.1943-278X

Kang, S. H., \& Gratch, J. (2010). Virtual humans elicit socially anxious interactants' verbal self-disclosure. Computer Animation and Virtual Worlds, 21(3-4), 473-482.

Kiuhara, S. A., \& Huefner, D. S. (2008). Students with psychiatric disabilities in higher education settings: The Americans with Disabilities Act and beyond. Journal of Disability Policy Studies, 19(2), 103-113. 
Knox, K. L., Litts, D. A., Talcott, G. W., Feig, J. C., \& Caine, E. D. (2003). Risk of suicide and related adverse outcomes after exposure to a suicide prevention program in the US Air Force: Cohort study. BMJ, 327:1376. doi:10.1136/bmj.327.7428.1376

Lai, D. T., Cahill, K., Qin, Y., \& Tang, J. L. (2010). Motivational interviewing for smoking cessation. Cochrane Database of Systematic Reviews, CD006936. doi:10.1002/14651858.CD006936.pub2

Lapierre, C. B., Schwegler, A. F., \& LaBauve, B. J. (2007). Posttraumatic stress and depression symptoms in soldiers returning from combat operations in Iraq and Afghanistan. Journal of Traumatic Stress, 20(6), 933-943. doi:10.1002/jts.20278

Lucas, G. M., Gratch, J., King, A., \& Morency, L. P. (2014). It's only a computer: Virtual humans increase willingness to disclose. Computers in Human Behavior, 37, 94-100.

Lundahl, B., \& Burke, B. L. (2009). The effectiveness and applicability of motivational interviewing: A practice-friendly review of four meta-analyses. Journal of Clinical Psychology, 65(11), 12321245. doi:10.1002/jclp.20638

Mann, J. J., Apter, A., Bertolote, J., Beautrais, A., Currier, D., Haas, A., \& Hendin, H. (2005). Suicide prevention strategies: A systematic review. JAMA, 294(16), 2064-2074. doi:10.1001/jama.294.16.2064

Mantovani, F., Castelnuovo, G., Gaggioli, A., \& Riva, G. (2003). Virtual reality training for health-care professionals. CyberPsychology \& Behavior, 6(4), 389-395.

Megivern, D., Pellerito, S., \& Mowbray, C. (2003). Barriers to higher education for individuals with psychiatric disabilities. Psychiatric Rehabilitation Journal, 26(3), 217-231.

Miller, W. R. (1983). Motivational interviewing with problem drinkers. Behavioral Psychotherapy, 11(2), 147-172. doi:10.1017/S0141347300006583

Miller, W. R., \& Rollnick, S. (2012). Motivational interviewing: Helping people change. New York: Guilford Press.

Milliken, C. S., Auchterlonie, J. L., \& Hoge, C. W. (2007). Longitudinal assessment of mental health problems among active and reserve component soldiers returning from the Iraq war. JAMA: Journal of the American Medical Association, 298(18), 2141-2148. doi:10.1001/jama.298.18.2141

Nestel, D., \& Tierney, T. (2007). Role-play for medical students learning about communication: Guidelines for maximizing benefits. BMC Medical Education, 7(1), 3. doi:10.1186/1472-6920-73

Payne, J., Jackson, E., Ryan, L., Hoscheidt, S., Jacobs, J., \& Nadel, L. (2006). The impact of stress on neutral and emotional aspects of episodic memory. Memory, 14(1), 1-16. doi:10.1080/09658210500139176

Ramchand, R., Schell, T. L., Karney, B. R., Osilla, K. C., Burns, R. M., \& Caldarone, L. B. (2010). Disparate prevalence estimates of PTSD among service members who served in Iraq and Afghanistan: Possible explanations. Journal of Traumatic Stress, 23(1), 59-68. doi:10.1002/jts

Read, J. P., Ouimette, P., White, J., Colder, C., \& Farrow, S. (2011). Rates of DSM-IV-TR trauma exposure and posttraumatic stress disorder. Psychological Trauma: Theory, Research, Practice, and Policy, 3(2), 148-156. doi:10.1037/a0021260

Reno, R. R., \& Kenny, D. A. (1992). Effects of self-consciousness and social anxiety on self-disclosure among unacquainted individuals: An application of the social relations model. Journal of Personality, 60(1), 79-94. 
Rubak, S., Sandbæk, A., Lauritzen, T., \& Christensen, B. (2005). Motivational interviewing: A systematic review and meta-analysis. British Journal of General Practice, 55(513), 305-312.

Ryan, S. W., Carlstrom, A. H., Hughey, K. F., \& Harris, B. S. (2011). From boots to books: Applying Schlossberg's Model to transitioning American veterans. NACADA Journal, 31(1), 55-62.

Schurtz, D., Cerel, J., \& Rodgers, P. (2010). Myths and facts about suicide from individuals involved in suicide prevention. Suicide and Life-Threatening Behavior, 40(4), 346-352. doi:10.1521/suli.2010.40.4.346

Smyth, J. M., Hockemeyer, J. R., Heron, K. E., Wonderlich, S. A., \& Pennebaker, J. W. (2008). Prevalence, type, disclosure, and severity of adverse life events in college students. Journal of American College Health, 57(1), 69-76.

Suicide Prevention Resource Center. (2014). Best Practices Registry. Retrieved from Section III: Adherence to Standards: http://www.sprc.org/bpr/section-iii-adherence-standards

Thompson, K. M. (2007). Alcohol-related legal infractions and student retention. Journal of Studies on Alcohol and Drugs, 68(5), 689-696.

Turner, A. L., \& Berry, T. R. (2000). Counseling center contributions to student retention and graduation: A longitudinal assessment. Journal of College Student Development, 41(6), 627-636.

United Nations Department for Policy Coordination and Sustainable Development. (1996). Prevention of suicide guidelines for the formulation and implementation of national strategies. New York: United Nations

VanBuskirk, K. A., \& Wetherell, J. L. (2013). Motivational interviewing with primary care populations: A systematic review and meta-analysis. Journal of Behavioral Medicine, 1-13. doi:10.1007/s10865-013-9527-4

Vasilaki, E. I., Hosier, S. G., \& Cox, W. M. (2006). The efficacy of motivational interviewing as a brief intervention for excessive drinking: A meta-analytic review. Alcohol and Alcoholism, 41(3), 328335. doi:10.1093/alcalc/agl016

Wilson, S. B., Mason, T. W., \& Ewing, M. J. M. (1997). Evaluating the impact of receiving universitybased counseling services on student retention. Journal of Counseling Psychology, 44(3), 316320

Wyman, P. A., Brown, H. C., Inman, J., Cross, W., Schmeelk-Cone, K., Guo, J., \& Pena, J. B. (2008). Randomized trial of a gatekeeper program for suicide prevention: 1-year impact on secondary school staff. Journal of Consulting and Clinical Psychology, 76(1), 104. doi:10.1037/0022006X.76.1.104 